\title{
Bullying, Victimization, School Performance, and Mother-Child Relationship Quality: Direct and Transactional Associations
}

\author{
Kostas A. Fanti and Stelios N. Georgiou \\ Department of Psychology, University of Cyprus, P.O. Box 20537, 1678 Nicosia, Cyprus \\ Correspondence should be addressed to Kostas A. Fanti; kfanti@ucy.ac.cy and Stelios N. Georgiou; stege@ucy.ac.cy
}

Received 27 February 2013; Accepted 18 April 2013

Academic Editor: Byongook Moon

Copyright (c) 2013 K. A. Fanti and S. N. Georgiou. This is an open access article distributed under the Creative Commons Attribution License, which permits unrestricted use, distribution, and reproduction in any medium, provided the original work is properly cited.

\begin{abstract}
The current investigation examines longitudinal differences between bullies, victims, and bully victims in terms of the quality of their relationship with their parents and school performance. We also investigate the transactional association between the quality of the parent-child relationship and bullying behavior, after taking into account the longitudinal association among bullying, victimization, and school performance. The sample consisted of 895 mothers and their children who participated in the NICHD Study of Early Child Care. According to the findings, children in the cooccurring bully victim group were at higher risk to experience continuous conflict with their mothers and to perform worse academically. The findings also offer support for the hypothesized transactional association between bullying and parent-child conflict and closeness. Further, a positive longitudinal transactional association between victimization and parent-child closeness was identified. Finally, school performance was positively related to victimization but was unrelated to bullying behavior.
\end{abstract}

\section{Introduction}

Bullying at school is a disturbing phenomenon with serious short-term and long-term consequences for both the victim and the perpetrator (e.g., [1-3]). As such, it deserves to be empirically examined so that its parameters can be identified. According to Olweus [4], bullying is defined as a physical, verbal, or psychological attack or intimidation that is intended to cause fear, distress, or harm to the victim. To be considered as bullying, an aggressive act must meet three criteria: (1) it must be intentional, (2) it must be systematic, and (3) it must be characterized by an imbalance of power $[5,6]$. Victims of this painful experience are usually students who are perceived as vulnerable, submissive, or different $[7,8]$ by peers who are in a dominant role, either by virtue of their own strength or by virtue of being associated with a powerful group [9].

In addition to the bully and passive victim groups, a group of children exhibiting bullying behavior but who are also the victims of bullying has been identified. This group, named the bully victim or the aggressive victim group, has been linked to greater individual and contextual problems [10-13]. Based on these findings, the initial purpose of the current investigation is to identify groups of children exhibiting only bullying behavior, experiencing only victimization, and exhibiting cooccurring bullying and victimization across childhood and to examine differences between the identified groups in terms of the quality of their relationship with their parents and school performance using longitudinal data. The second aim of the current study is to investigate the reciprocal association between the quality of the parent-child relationship and bullying behavior, following Sameroff and MacKenzie's [14] transactional model of development.

1.1. School Performance. A number of studies investigated the association between school performance and bullying and victimization, and the majority of these studies suggested that victims of bullying perform worse academically compared to bullies and noninvolved children [15-19]. Moreover, some studies that took into account the cooccurrence between bullying and victimization provided evidence that victims and bully victims were more likely to have low school achievement compared to bullies and noninvolved children, while other studies indicated that the bully victim group might 
be at higher risk for low academic achievement [17, 20, 21]. Adding to prior cross-sectional work, the present study aims to compare how bullies, victims, and bully victims perform academically from the beginning to the end of elementary school. We expect that noninvolved children and bullies will perform better at school compared to passive victims and aggressive victims.

\subsection{Parent-Child Relationship Quality. The bullying literature} has also provided sufficient evidence linking the parentchild relationship to both bullying and victimization. For example, Baldry and Farrington [22] have shown that bullies compared to nonbullies tend to disagree more with their parents. Additionally, Bowers et al. [10] found that families of bullies and bully victims were less cohesive, characterized by lower warmth and higher hostility compared to children not engaging in bullying behaviors, while families of victims were characterized by high levels of cohesion. Stevens et al. [13] presented similar evidence in that bullies and bully victims perceived their families as less cohesive and expressive with higher conflict as compared to victims and noninvolved children, although victims did not differ from noninvolved children in terms of conflict or cohesion. According to these studies families of both bullies and bully victims seem to be characterized by high conflict and low connectedness. However, Schwartz et al. [23] provided evidence that the bully victim group might be at higher risk to experience hostility by their mothers compared to bullies, victims, and noninvolved children, indicating that the bully victim group might constitute a higher risk group. Interestingly, Schwartz et al. [23] did not find any evidence suggesting that groups of children exhibiting pure or combined levels of bullying and victimization differed in terms of maternal warmth. Even though there are some inconsistencies in the literature investigating differences between bullies, victims, and bully victims; most of the studies suggest that victims, just as noninvolved children, experience a positive parent-child relationship, characterized by high closeness, warmth, and low conflict. The goal of the present study is to replicate these cross-sectional findings using longitudinal data in order to identify differences between bullies, victims, and bully victims in terms of their relationship with their mothers during childhood. Based on previous cross-sectional research, we expect that bullies and bully victims will experience a negative parent-child relationship, high conflict, and low closeness, from the beginning to the end of elementary school. In contrast, we expect that victims and noninvolved children will experience a positive parent-child relationship across time.

1.3. Transactional Association. Finding that the quality of the parent-child relationship is different among subgroups of children engaging or not in bullying and victimization behaviors might suggest an association between these variables, although the direction of this association is not specified. For example, we can assume that parental practices characterized by absence of a warm relationship with the child, coldness, indifference, or even hostility and conflict are especially harmful and lead to bullying behavior. On the other hand, we can also assume that bullying behavior, which is related to opposition, defiance, and aggression towards parents [4], might elicit negative reactions from parents. There are a number of studies providing evidence that parenting characteristics influence bullying behavior [22, 24-28], although there are also studies suggesting that bullying, aggressive, and antisocial behavior is negatively related to the quality of the parent-child relationship and to decreases in nurturing parental behavior and involvement [29-32].

Therefore, it is important to empirically examine the direction of effects between the parent-child relationship quality and bullying behavior in order to provide evidence for reciprocal or transactional associations between these variables; the second aim of the current investigation. According to Sameroff and MacKenzie [14], the transactional model can be conceptualized as the continuous bidirectional or reciprocal influences between the child and the child's context. Following the transactional model, we conceptualize the development of bullying behavior at school as a product of the continuous reciprocal influences between children and their parents. As a result, we expect that the quality of the parent-child relationship within the home will influence the children's bullying behavior at school but also that bullying behavior within the school setting will negatively influence the parent-child relationship.

Although there are a number of transactionally oriented studies investigating the association between parenting variables and child behavioral problems (e.g., [29, 33-39]), very little is known about the transactional association between parenting and bullying behavior. By investigating a transactional model of development, we will be able to provide evidence for the directionality of the parent and child effects across time. Do parents influence their child's behavior, do children influence parenting, or is there a cycle of coercive processes in which both negative parenting and negative child behaviors exacerbate each other, as Patterson [40] suggested? Furthermore, bullying and victimization problems tend to be comorbid among children [11-13], and inclusion of both in the same model can clarify the unique transactional effects of bullying and victimization problems over time. The present study uses a longitudinal cross-lag model over three waves of measurement (grades 3, 5, and 6) to investigate the reciprocal link between children's relationships with their parents and bullying and victimization experiences within the school setting. Longitudinal cross-lag models are advantageous because they control for the association between the variables at each time point of measurement, taking into account the cooccurrence between bullying and victimization across time.

Moreover, as previously mentioned, a number of studies have linked bullying and victimization to the child's academic achievement or school performance. To control for the potential covariation of these variables, we included school performance as another covariate in the transactional model under investigation. However, the reciprocal association between school performance and bullying and victimization behaviors is also of interest. Previous studies suggested that low school performance cannot explain student's bullying behavior, and 
children engaging in this type of antisocial behavior do not necessarily have problems with their school performance [4, $18,41]$. On the other hand, victimization experiences might be negatively related to school performance because of the anxiety and lower concentration to school work associated with being victimized $[42,43]$. In addition, students who perform well at school might be more likely to be victimized [18]. Therefore, we expect a reciprocal association between academic achievement and victimization but not between academic achievement and bullying behavior.

Further, we control for gender in our cross-lag analyses because boys are at higher risk to engage in aggressive behaviors than girls (e.g., [44, 45]). In general, studies report that compared to girls boys are more likely to engage in bullying behavior, although no gender differences in the prevalence rates of victimization have been reported $[3,46$, 47]. Also, girls experience higher quality relationships with their parents (e.g., $[48,49])$ and perform better academically compared to boys [50], providing additional evidence for the importance of including gender as a control variable in our analysis.

1.4. Present Study. Preliminary research suggests that children involved in bullying are a heterogeneous population and can be disaggregated on the basis of the cooccurrence between bullying and victimization. However, it is unknown whether these subgroups differ longitudinally on measures of school performance and parent-child relationship; the first aim of the current study. The second aim of the current study is the investigation of the transactional association between the quality of the parent-child relationship and the child's behavioral problems, taking into account gender differences and the cooccurrence between bullying, victimization, and school performance. In sum, the following hypotheses will be tested.

(1) Children in the bully and bully victim groups are expected to experience more conflict with their mothers and less closeness compared to victims and noninvolved children.

(2) Victims and bully victims are expected to perform worse academically compared to bullies and noninvolved children.

(3) A transactional model of development among bullying, victimization, and mother-child relationship quality is hypothesized to be identified, after controlling for gender and school performance.

(4) School performance and victimization are hypothesized to be reciprocally associated.

\section{Method}

2.1. Participants. The present study used data from the National Institute of Child Health and Human Development (NICHD) Study of Early Child Care. This study was conducted by the NICHD Early Child Care Research Network (ECCRN) supported by NICHD through a cooperative agreement that calls for scientific collaboration between the grantees and the NICHD staff. Participants were recruited from different hospitals across 10 locations in the United States (Little Rock, AR; Irvine, CA; Lawrence, KS; Boston, MA; Philadelphia, PA; Pittsburgh, PA; Charlottesville, VA; Morganton, NC; Seattle, WA; Madison, WI). A total of 8,986 women gave birth during the sampling period (January of 1991 and November of 1991) across the different locations, and $60 \%(5,416)$ of those women agreed to be contacted for a telephone interview. Of the women who agreed to participate, $56 \%$ were selected based on conditional random sampling in order to assure that the sample was representative of single mothers, poverty status, ethnic minority, and low maternal education. From this sample, participants were excluded if (a) mothers were younger than 18 at the time of the child's birth, (b) families were planning to move before the completion of the study, (c) children were born with disabilities or remained in the hospital more than seven days postpartum, and (d) mothers could not communicate sufficiently in English. One thousand five hundred and twenty-five families were selected as eligible, but only 1,364 completed the home interview when the infant was 1 month old, and these families comprised the final sample of the study. Of the final sample, $53 \%$ of the children were male, $24 \%$ were of minority status, $11 \%$ of the mothers did not complete high school, $24.3 \%$ scored below the poverty line, and $14 \%$ were single.

The analyses for the present study were based on 895 participants who had completed reports on the bullying and victimization measures during grade 3 (age 9), grade 5 (age 11 ), and grade 6 (age 12). Similarly to the NICHD final sample, the sample used for the current study was diverse in terms of gender (50.1\% male), ethnicity (76.5\% white, 6.1\% Hispanic, 12.1\% African American, 1.3\% Asian, and 4\% other minority groups), parental educational level, and marital status $(9.3 \%$ of the mothers had not completed high school and $21.7 \%$ were single). According to chi-square analyses and $t$-tests of attrition, the sample used for the current study $(N=895)$ did not differ in any of the demographics and the study's measures when compared to children who were excluded from the analyses due to incomplete data $(N=469)$.

\subsection{Measures}

2.2.1. Bullying and Victimization. Perceived victimization and the engagement in physical and direct and indirect verbal bullying behaviors with school classmates were based on The Perception of Peer Support Scale (PPSS, [51, 52]). In the present study the scale was administered three times, in grades 3, 5 , and 6. Participating children responded by choosing a number from 1 to 5 (Never, Hardly ever, Sometimes, Most of the time, and Always). There are two subscales, one measuring perceived victimization and the other measuring engagement in bullying behavior. The perceived victimization subscale asks children to report the extent to which they had experienced peer aggression in their class at school using the following questions: does anyone in your class ever: (1) pick on you at school, (2) say mean things to you at school, (3) say bad things about you to other kids at school, (4) hit you at school. An overall victimization score was calculated by summing the four items with good internal reliability during 
grade $3(\alpha=.76)$, grade $5(\alpha=.81)$, and grade $6(\alpha=.85)$. The engagement in bullying behaviors subscale asks children to report whether they ever exhibited the following behaviors in their school: (1) pick on other kids, (2) hit kids that are weaker than them, (3) say mean things to other kids, (4) do namecalling with other kids at school. An overall bullying score was calculated by summing the four items with good internal consistency during grade 3 ( $\alpha=.77)$, grade $5(\alpha=.78)$, and grade $6(\alpha=.83)$.

2.2.2. School Performance. The children's school performance from grade 1 to grade 6 was measured by means of the Mock Report Card [53]. Teacher's rated their students' school performance on a 5 -point scale $(1=$ below grade level, $5=$ excellent) in six subjects: reading, oral language, written language, math, social studies, and science. The mean of the teacher ratings in the 6 subjects was used to indicate the students' performance in school. Cronbach's alpha was consistently high across the six waves of measurement $(\alpha=$ $.93-.95)$.

2.2.3. Closeness and Conflict. Between the mother and the child during grades $1,3,4,5$, and 6 were measured by means of the Child-Parent Relationship Scale (CPRS, [54]). The items in the CPRS were derived from attachment theory, and the measure enabled mothers to report the child's attachment behaviors at home. The items involved the mother's feelings and beliefs about her relationship with the child and about the child's behavior toward the parent. The CPRS asks parents to rate items on a 5-point, Likert-type scale, ranged from $1=$ "Definitely does not apply" to 5 = "definitely applies". The conflict score was computed as the sum of 7 items (e.g., "my child easily becomes angry at me"), with higher scores indicating more conflict between the mother and the child. Cronbach's alpha ranged from .81 to .87 for the five measurement waves. The closeness score was computed as the sum of 8 items (e.g., "I share an affectionate and warm relationship with my child"), with higher scores indicating more closeness between the mother and the child. Cronbach's alpha ranged from .65 to .76 for the five measurement waves.

2.3. Plan of Analysis. We conducted growth curve modeling to investigate how school performance and the parent-child closeness and conflict changed across time using the Mplus 6.1 statistical software [55]. The use of growth curve modeling enabled the identification of the average intercept and growth terms for each measured variable: school performance, closeness, and conflict. The residual growth factors were used to suggest whether there is variability in terms of the initial levels of the variables and in terms of change over time. Growth curve modeling uses a polynomial function to model the relationship between an attribute (i.e., school performance) and time [55]. For example, in the case that we identify a curvilinear pattern of change, the function takes the form [56]

$$
y_{t t}=\beta_{o}+\beta_{1} \operatorname{grade}_{t t}+\beta_{2} \operatorname{grade}_{t t}^{2}+\varepsilon,
$$

where $y_{t}$ is a latent variable which characterizes the level of conflict or closeness between the mother and the child or the child's school performance. Grade ${ }_{\text {lt }}$ refers to the grade level of participant $\iota$ at time $t$, grade ${ }_{\iota t}{ }^{2}$ is the square of the participant $i$ 's grade level at time $t$, and $\varepsilon$ is a disturbance assumed to be normally distributed with zero mean and constant variance. The model's coefficients, $\beta_{o}, \beta_{1}$, and $\beta_{2}$, determine the average shape of the trajectory. Three standard fit indexes were used in addition to the chi-square statistic to evaluate model fit: The Root Mean-square Error of Approximation (RMSEA), Standardized Root Mean Residual (SRMR), and the Comparative Fit Index (CFI). Cutoff values close to .06 for RMSEA, .08 for SRMR, and .95 for CFI are considered ideal $[57,58]$.

In the case that variability was identified in the average intercept or growth terms, we proceeded to investigate differences between the identified groups of children engaging in bullying or victimization. Multiple group mixture modeling (MGMM) is suitable for this type of analysis because it provides information in terms of how different groups of individuals differ on continuous measures that are collected longitudinally [55]. More specifically, MGMM is used when there is one categorical variable (i.e., different groups of children based on their engagement in bullying behavior) for which class membership is known and equal to the groups identified in the sample (i.e., noninvolved, bullies, victims, and bully victims). Further, MGMM allows for the investigation of how the identified categorical groups in the sample change over time. Similar to growth curve modeling, MGMM uses a polynomial function to model the relationship between an attribute and time [55]. The function takes the form

$$
y_{t t}^{j}=\beta_{\mathrm{o}}^{j}+\beta_{1}^{j} \operatorname{grade}_{t t}+\beta_{2}^{j} \operatorname{grade}_{t t}{ }^{2}+\varepsilon,
$$

where $y_{t t}^{j}$ is a latent variable which characterizes the level of the variables under investigation for participant $\iota$ at time $t$

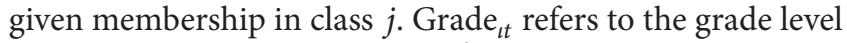
of participant $\iota$ at time $t, \operatorname{grade}_{\iota t}{ }^{2}$ is the square of the participant $\iota$ 's grade level at time $t$, and $\varepsilon$ is a disturbance assumed to be normally distributed with zero mean and constant variance. The model's coefficients, $\beta_{0}^{j}, \beta_{1}^{j}$, and $\beta_{2}^{j}$, determine the shape of the trajectory. The coefficients are superscripted by $j$ to denote that the groups identified in the sample vary across different levels of the categorical variable (different groups in terms of engagement in bullying or victimization), which allows for cross-group differences in the shape of the trajectories.

Finally, in order to investigate the transactional association between the parent-child relationship and bullying and victimization experiences at school, we performed crosslagged path analysis in Mplus 6.1. This model allows for the investigation of whether parent-child conflict and closeness, school performance, and bullying and victimization will be reciprocally related over time. The use of a cross-lag model allows testing causal predominance by investigating whether a parent effect model, a child effect model, or a bidirectional model is in effect. After testing the basic model (Figure 1), nonsignificant paths were dropped from the model and the model was tested again. As with prior analysis, the RMSEA, SRMR, and CFI were used as model fit indexes for the crosslagged path analyses. 
TABLE 1: Bullying and victimization mean (and standard deviation) scores.

\begin{tabular}{lccc}
\hline Measured variable & Grade 3 & Grade 5 & Grade 6 \\
\hline Bullying & $4.82(1.67)$ & $5.15(1.81)$ & $5.46(2.04)$ \\
Victimization & $7.32(3.17)$ & $7.16(3.08)$ & $6.94(2.79)$ \\
\hline
\end{tabular}

Note that values not enclosed in parenthesis represent the mean of each variable and the values enclosed in parenthesis represent the standard deviation.

\section{Results}

3.1. Descriptive Statistics. Table 1 shows the means and standard deviations for bullying and victimization. According to pair wise $t$-test analyses, children reported higher bullying at grade 6 compared to grade $5, t(895)=4.94, P<.001$, and at grade 5 compared to grade $3, t(895)=4.84, P<.001$. Victimization decreased form grade 5 to grade $6, t(895)=$ 2.26, $P<.05$, although there were no statistically significant differences between grade 3 and grade $5, t(895)=1.34, P=$ .15 .

To classify individuals in the noninvolved, bully only, victim only, and bully victim groups, we chose a cutoff score corresponding to one Standard Deviation (SD) above the mean for bullying and victimization, as done by previous research (e.g., [11]). During each time point, all children scoring below the cutoff score on both bullying and victimization were classified in the noninvolved group. Children scoring $1 \mathrm{SD}$ above the mean on both bullying and victimization were classified in the bully victim group, children scoring 1 $\mathrm{SD}$ above the mean on bullying but below the cutoff score on victimization were classified in the bully only group, and children scoring below the cutoff score on bullying but $1 \mathrm{SD}$ above the mean on victimization were classified in the victim only group. During grade $3,79.2 \%(n=709)$ of the sample comprised the low group, $8.7 \%(n=78)$ the victim only group, $7.5 \%(n=67)$ the bullying only group, and $4.6 \%(n=$ $41)$ the bully victim group. During grade $5,72.3 \%(n=647)$ of the sample comprised the low group, $7.9 \%(n=71)$ the victim only group, $13.2 \%(n=118)$ the bullying only group, and $6.6 \%(n=59)$ the bully victim group. During grade $6,74.2 \%$ $(n=664)$ of the sample comprised the low group, $12.4 \%$ ( $n=111)$ the victim only group, $9.2 \%(n=82)$ the bullying only group, and $4.2 \%(n=38)$ the bully victim group.

We then use the cross-tab analysis function in SPSS 19 to classify children as noninvolved, bullies only, victims only, and bully victims across different points during the three waves of measurement. According to our findings, 54\% of the children remained uninvolved across time. Children in the noninvolved group reported that they never or hardly ever participated in bullying or victimization. Additionally, $16.2 \%$ of the children engaged in pure bullying, $15.1 \%$ were the victims of bullying, and $4.8 \%$ exhibited cooccurring bullying and victimization at some point in development either on grade 3,5 , or 6 . An additional $9.9 \%$ of children exhibited bullying or victimization or both at different time points. Thus, this final group of children was inconsistent in terms of which behavior they exhibited across time, and they might be bullies during one time and victims or bully victims during another
TABLE 2: Growth factor parameter estimates.

\begin{tabular}{lccc}
\hline Groups & Intercept (SE) & $\begin{array}{c}\text { Linear slope } \\
(\mathrm{SE})\end{array}$ & $\begin{array}{c}\text { Quadratic } \\
\text { term }(\mathrm{SE})\end{array}$ \\
\hline $\begin{array}{l}\text { School } \\
\text { performance }\end{array}$ & & & \\
$\quad$ Uninvolved & $3.518(.053)^{* *}$ & $.003(.029)$ & $.002(.004)$ \\
$\quad$ Victim only & $3.424(.098)^{* *}$ & $-.064(.057)$ & $.006(.008)$ \\
Bully only & $3.350(.095)^{* *}$ & $.056(.055)$ & $-.009(.007)$ \\
Bully victim & $3.207(.200)^{* *}$ & $.001(.108)$ & $-.002(.014)$ \\
Occasional & $3.211(.135)^{* *}$ & $-.113(.079)$ & $.011(.011)$ \\
Mother-child & & & \\
conflict & & & \\
Uninvolved & $14.583(.357)^{* *}$ & $.363(.189)^{*}$ & $-.019(.026)$ \\
Victim only & $15.384(.677)^{* *}$ & $.672(.349)^{*}$ & $-.028(.048)$ \\
Bully only & $16.087(.638)^{* *}$ & $-.284(.339)$ & $.084(.047)$ \\
Bully victim & $16.314(1.429)^{* *}$ & $.059(.892)$ & $.079(.131)$ \\
Occasional & $17.433(.919)^{* *}$ & $-.006(.454)$ & $.035(.066)$ \\
\hline Note. ${ }^{*} P<.05,{ }^{* *} P<.01 ;$ SE: standard error. &
\end{tabular}

time point. This group will be referred to as the occasional bully or victim group. These five groups comprised the final groups to be used in subsequent analyses.

3.2. Growth Modeling. To investigate the average trajectories of participants' school performance across time, a growth curve model was initially estimated. The growth model fit the data well, $\chi_{(6, N=895)}^{2}=49.81$, RMSEA $=.060$ (RMSEA CI: $.043 \mid .077)$, SRMR $=.022$, and CFI $=.989$. The unstandardized intercept $(i=3.431, \mathrm{SE}=.039, P<.001)$ was significant, although the linear slope $(s=-.009, \mathrm{SE}=.022, P=$ $.67)$ and the quadratic acceleration term $(q=.002, \mathrm{SE}=.003$, $P=.59)$ were not significant, suggesting that on average students final school performance did not change from their initial school performance across time (Figure 1). In addition, the unstandardized residual intercept $(i=.642, \mathrm{SE}=.091$, $P<.001)$, the residual linear slope $(s=.104$, SE $=.028$, $P \leq .001)$, and the quadratic acceleration term $(q=.002$, $\mathrm{SE}=.001, P<.001)$ were significant indicating significant variability between subjects in terms of initial levels of school performance and in terms of change over time. Additional analysis used MGMM modeling to investigate for differences between the identified groups. Figure 1 shows the mixed quadratic growth model resulting from the MGMM, and Table 2 shows the unstandardized intercept, linear and quadratic terms for the different groups. According to Figure 1, only the uninvolved children scored above average on academic achievement. The bullies did not differ much from the victims in terms of school performance, and both of these groups scored better in comparison to children who exhibited some combination of bullying and victimization. The occasional bullies or victims had the worse school performance over time, although initially this group's school performance was similar to the bully victim group.

As with previous analyses, to investigate the average trajectories of students' closeness with their mothers across time, 


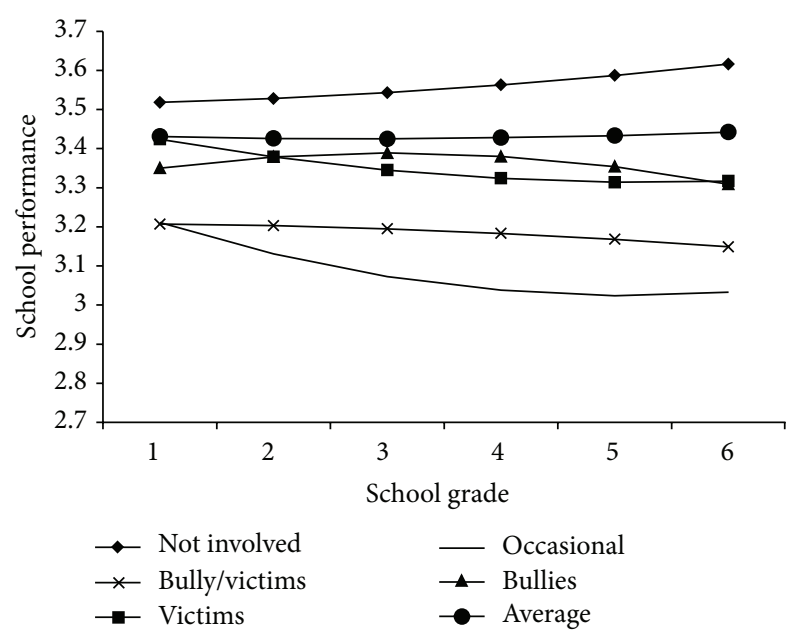

FIGURE 1: Mixture group growth model examining differences between groups in terms of school performance.

a latent growth curve model was initially estimated. The growth model fit the data well, $\chi_{(6, N=895)}^{2}=24.67$, RMSEA $=$ .059 (RMSEA CI: .036 | .084), SRMR $=.153$, and CFI $=$ .990 . The unstandardized intercept $(i=38.260, \mathrm{SE}=.129$, $P<.001)$, and the linear slope $(s=-.350, \mathrm{SE}=.085, P<$ .001 ) were significant, although the quadratic acceleration term $(q=-.002, \mathrm{SE}=.012, P=.87)$ was not significant, suggesting that on average mother-child closeness decreased linearly across time. However, the unstandardized residual intercept $(i=-.538, \mathrm{SE}=2.319, P=.81)$ and the residual linear slope $(s=.828, \mathrm{SE}=.588, P=.159)$ were not significant, and only the quadratic acceleration term $(q=.027$, $\mathrm{SE}=.009, P=.004)$ was significant indicating that there was no significant variability between subjects in terms of initial levels of mother-child closeness and in terms of linear change over time. Additional analysis used MGMM to investigate differences between groups by holding the intercept and linear terms constant and investigating for differences between the groups in terms of curvilinear change. However, an inspection of the graph did not indicate any curvilinear differences between the groups under investigation, and the quadratic acceleration terms were not significant. Based on these findings, we concluded that closeness between mother and children decreased across time in a similar fashion for all children in the sample.

Finally, we investigated the average trajectories of students' conflict with their mothers. The growth model fit the data well, $\chi_{(6, N=895)}^{2}=20.11$, RMSEA $=.051$ (RMSEA CI: $.028 \mid .077)$, SRMR $=.018$, and CFI $=.995$. The unstandardized intercept $(i=15.307, \mathrm{SE}=.269, P<.001)$ and the linear slope $(s=.260, \mathrm{SE}=.142, P<.05)$ were significant, although the quadratic term $(q=.005, \mathrm{SE}=.020$, $P=.78)$ was not significant, suggesting that mother-child conflict increased linearly across time (Figure 2 ). In addition, the unstandardized residual intercept $(i=25.119, \mathrm{SE}=$ 7.637, $P<.001)$, the residual linear slope $(s=3.890$, $\mathrm{SE}=$ $1.733, P<.05)$, and the quadratic acceleration term $(q=$ $.089, \mathrm{SE}=.026, P<.001)$ were significant, indicating

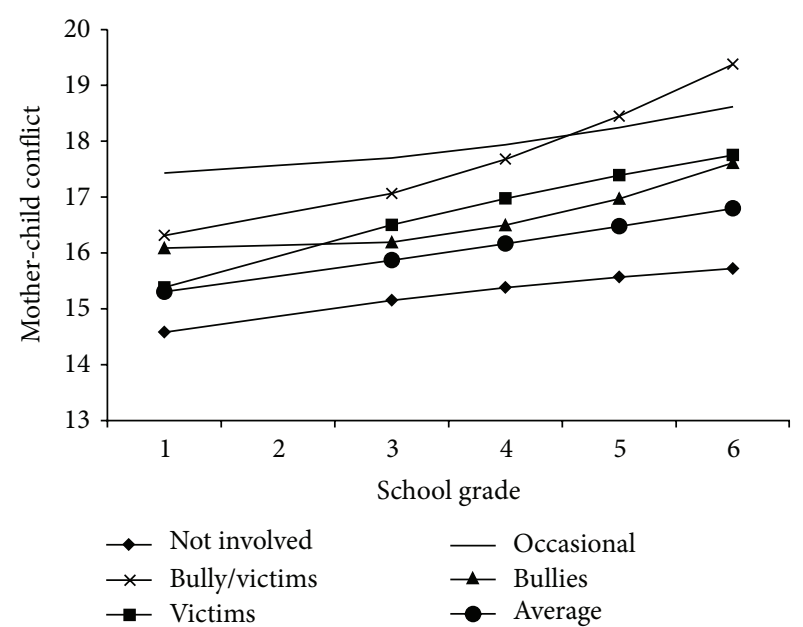

FIGURE 2: Mixture group growth model examining differences between groups in terms of mother-child conflict.

significant variability between-subjects in terms of initial levels of mother-child conflict and change over time. Additional analysis used MGMM to investigate differences between groups. Figure 2 shows the mixed quadratic growth model resulting from the multiple group mixture growth model analyses, and Table 2 shows the unstandardized intercept, linear and quadratic terms for the different groups. According to Figure 2, only the uninvolved children scored below average on mother-child conflict. The bully victim group and the occasional bully victim group experienced more conflict with their mothers in comparison to the other groups. Bully victims experienced less conflict with their mothers from grade 1 to grade 4 in comparison to the occasional bully victim group. Bullies and victims did not differ much in terms of mother-child conflict, and both groups tended to score lower than the co-occurring groups. The uninvolved and the victim only groups exhibited significant linear increase from grade 1 to grade 6 in terms of conflict with their mothers.

3.3. Cross-Lagged Path Analysis. The model under investigation is illustrated in Figure 3. The hypothesized model fit the data well based on the SRMR and the CFI fit indexes, $\chi_{(25, N=895)}^{2}=280.57$, RMSEA $=.107$ (RMSEA CI: .096 $\mid .118$ ), $\mathrm{SRMR}=.029$, and CFI $=.95$. The full model (Figure 3) was compared to a nested one with all nonsignificant paths being removed (Figure 4). The reduced model fit the data well based on all of the fit indexes, $\chi_{(52, N=895)}^{2}=311.28$, RMSEA $=.075$ (RMSEA CI: .067 $\mid .083$ ), SRMR $=.039$, and CFI $=.95$, and fit the data equally as well as the full model, $\Delta \chi_{(29, N=895)}^{2}=30.71, P=.38$. Therefore, we decided to proceed with the more parsimonious, reduced model. Not shown in Figure 4 are the correlations between the variables at each time point, which are presented in Table 3. According to Table 3, bullying was positively correlated with victimization and conflict across time and was negatively related to grade 5 closeness and grade 3 school performance. Victimization was positively related to grade 3 and grade 6 conflict and negatively to grade 3 school performance. Closeness was 


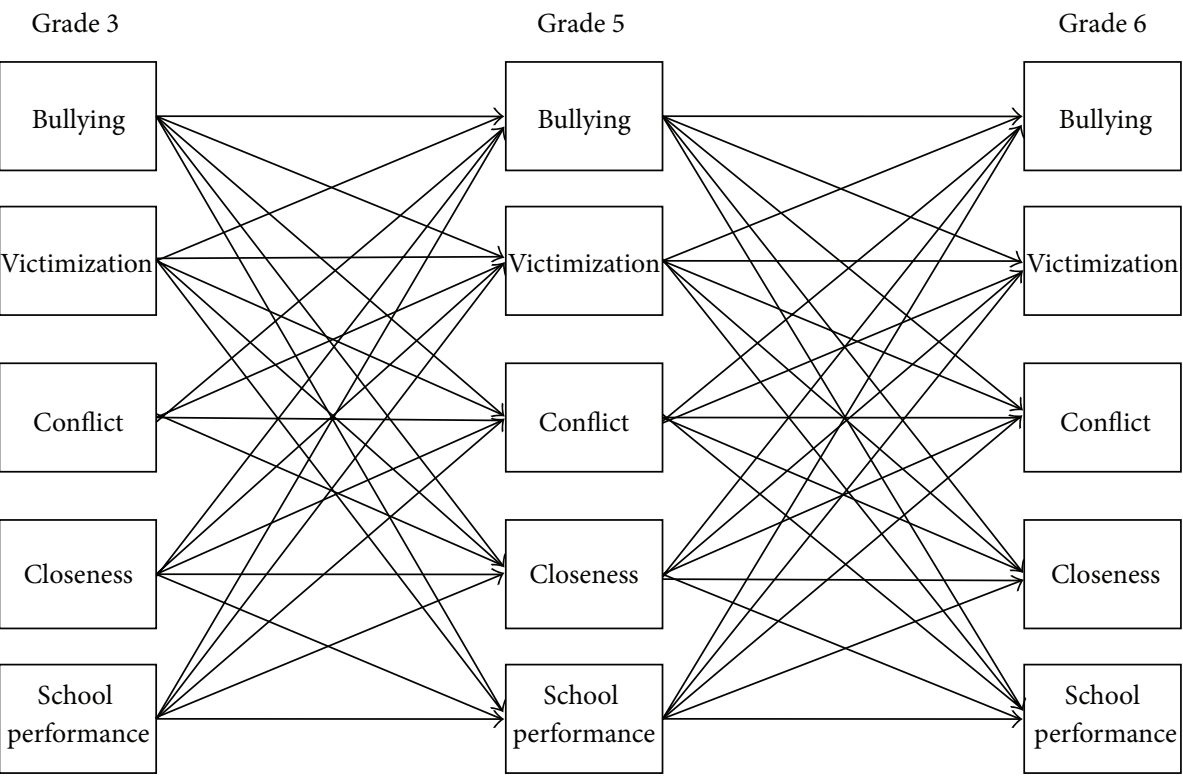

FIgURE 3: Initial path model. Note that not shown in the figure are the correlations between the variables at each time point.

Grade 3

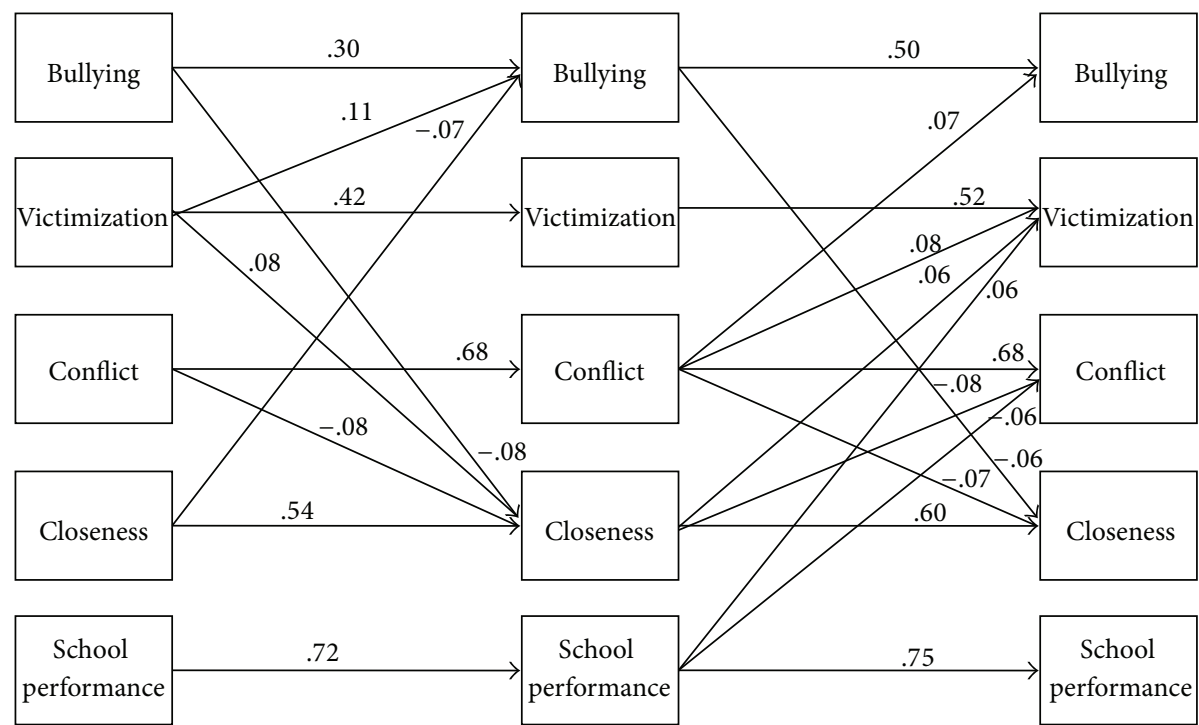

FIGURE 4: Final path model controlling for gender. Note that all paths are significant at the .05 level. Not shown in the figure are the correlations between the variables at each time point.

negatively related to conflict across time and positively to school performance at grade 3. School performance was negatively related to grade 3 and grade 6 conflict.

As previously mentioned, we also controlled for gender (coded with 1 for boys and 2 for girls), and based on the findings gender was significantly related to grade 5 bullying, $\beta$ $=-.07, \mathrm{SE}=.03, P<.05$, indicating that boys were more likely to exhibit bullying behavior in school, to grade 5 closeness, $\beta$ $=.06, \mathrm{SE}=.03, P<.05$, indicating that girls were closer to their mothers, and to grade 5 school performance, $\beta=.10$,
$\mathrm{SE}=.02, P<.001$, indicating that girls performed better at school than boys. Additionally, the autoregressive paths between grade 3 and grade 5 bullying, $\beta=.30, \mathrm{SE}=.03$, $P<.001$, victimization, $\beta=.42$, SE $=.03, P<.001$, closeness, $\beta=.54, \mathrm{SE}=.02, P<.001$, conflict, $\beta=.68, \mathrm{SE}=.02, P<.001$, and school performance, $\beta=.72, \mathrm{SE}=.02, P<.001$ were significant. Similarly, the grade 5 and grade 6 bullying, $\beta=$ $.50, \mathrm{SE}=.02, P<.001$, victimization, $\beta=.51, \mathrm{SE}=.02$, $P<.001$, closeness, $\beta=.60$, SE $=.02, P<.001$, conflict, $\beta=$ $.68, \mathrm{SE}=.02, P<.001$, and school performance, $\beta=.75$, 
TABLE 3: Path model correlations $(N=895)$.

\begin{tabular}{|c|c|c|c|c|c|c|c|c|c|c|c|c|}
\hline & \multicolumn{4}{|c|}{ Grade 3} & \multicolumn{4}{|c|}{ Grade 5} & \multicolumn{4}{|c|}{ Grade 6} \\
\hline & Bully & Victim & Conflict & Closen & Bully & Victim & Conflict & Closen & Bully & Victim & Conflict & Closen \\
\hline Victimization & $.42^{* *}$ & & & & $.36^{* *}$ & & & & $.27^{* *}$ & & & \\
\hline Conflict & $.08^{*}$ & $.15^{* *}$ & & & $.08^{*}$ & .05 & & & $.09^{* *}$ & $.07^{*}$ & & \\
\hline Closeness & -.05 & -.05 & $-.33^{* *}$ & & $-.07^{*}$ & -.02 & $-.26^{* *}$ & & -.02 & -.04 & $-.32^{* *}$ & \\
\hline School perform. & $-.07^{*}$ & $-.18^{* *}$ & $-.14^{* *}$ & $.13^{* *}$ & -.06 & -.02 & -.05 & -.03 & .01 & -.02 & $-.11^{* *}$ & .06 \\
\hline
\end{tabular}

Note that ${ }^{*} P<.05,{ }^{* *} P<.01$. Closen: closeness; school perform.: school performance.

$\mathrm{SE}=.02, P<.001$, autoregressive paths were all significant indicating substantial stability across time for all the variables under investigation.

As shown in Figure 4, bullying at grade 3 was negatively related to closeness at grade $5, \beta=-.08, \mathrm{SE}=.03, P<.01$, and grade 3 closeness was negatively related to bullying at grade $5, \beta=-.07 \mathrm{SE}=.03, P<.05$, suggesting a negative bidirectional association between these two variables. Grade 3 victimization was positively related to grade 5 closeness, $\beta=.08, \mathrm{SE}=.03, P<.05$, and bullying, $\beta=.11, \mathrm{SE}=.03$, $P<.001$. Grade 3 conflict was negatively related to grade 5 closeness, $\beta=-.08, \mathrm{SE}=.03, P<.01$. Bullying at grade 5 was negatively associated with closeness at grade $6, \beta=-.06, \mathrm{SE}=$ $.02, P<.05$. Grade 5 conflict was positively related to grade 6 bullying, $\beta=.07, \mathrm{SE}=.03, P<.05$, and victimization, $\beta=.08$, $\mathrm{SE}=.03, P<.01$. Grade 5 school performance was negatively related to grade 6 conflict, $\beta=-.06, \mathrm{SE}=.02, P<.01$, and positively to grade 6 victimization, $\beta=.06, \mathrm{SE}=.03, P<.05$. Closeness at grade 5 was positively related to victimization at grade $6, \beta=.06, \mathrm{SE}=.03, P<.05$. Finally, grade 5 conflict was negatively related to grade 6 closeness, $\beta=-.07, \mathrm{SE}=.02$, $P<.05$, and grade 5 closeness was negatively related to grade 6 conflict, $\beta=-.08, \mathrm{SE}=.02, P<.01$, suggesting a negative bidirectional association between these two variables.

\section{Discussion}

The present study contributes three key findings to prior research. First, using longitudinal data, the current study identified five different groups of children engaging in bullying and victimization: uninvolved, bully only, victim only, bully victim, and occasional bully victim. Second, using growth modeling analysis, we identified longitudinal differences among the identified bully victim groups on school performance and the mother-child relationship quality from grade 1 to grade 6 . Third, using cross-lag modeling, we investigated the longitudinal transactional association between school performance, parent-child relationship quality and child bullying and victimization experiences over a period of four years.

4.1. Identified Subgroups of Bullying and Victimization. Current longitudinal findings support the idea that bullying and victimization problems cooccur across time, and complement previous studies that identified groups of children exhibiting pure and cooccurring bullying and victimization behaviors [10-13]. However, the present study also provides evidence for an additional group of children who exhibit either bullying, victimization, or both during different time points, labeled the occasional bully victim group. It is argued that previous cross-sectional studies might provide misleading evidence when comparing groups of children exhibiting bullying, victimization, or both by not taking the occasional bully victim group into account. Additionally, we support findings of prior work suggesting that children exhibiting cooccurring bullying and victimization are at higher risk when compared to uninvolved, bully only, and victim only groups of children, in terms of school performance and parent-child conflict $[13,17,20,21,23]$. Similarly, the occasional bully victim group was also at high risk for low school performance and to experience high conflict with their mothers.

Moreover, the current findings contradict evidence that bullies are at higher risk to experience a more conflictual relationship with their mothers in comparison to victims [13]. This contradicting evidence might be due to our longitudinal design, since children who are identified in the current investigation as occasional bully victims might have been classified as bullies or victims by prior cross-sectional studies, which might have inflated their findings. In terms of closeness, our results support previous research that found no differences in mother-child closeness between bullies, victims, and bully victims [23], suggesting that mother-child closeness decreases across time as children mature and enter into adolescence. Importantly, findings indicated that bullies, victims, bully victims, and occasional bullies or victims start school at higher risk when compared to uninvolved children in terms of both school performance and mother-child conflict. Therefore, the combination of a negative home environment and low school achievement characterizing these higher risk subgroups of children might lead to the continuation of these behaviors across time.

4.2. Transactional Findings. Our findings provide support of the hypothesized transactional model between bullying, victimization, and the parent-child relationship quality. The results suggested that closeness and conflict contributed to bullying behavior and that bullying behavior influenced the closeness between parents and children, providing evidence of a transactional association between these variables. Therefore, as Patterson [40] suggested, the child's problematic behavior might be the result of the dynamic processes that unfold within the household between parents and children. The identified transactional findings were obtained despite 
controlling for the relatively strong stability of all five constructs over time and the intercorrelations between the variables at each time point of measurement. More specifically, there was a negative bidirectional association between closeness and bullying from grade 3 to grade 5, in which bullying behavior negatively influenced the closeness between mothers and children, and in turn mother-child closeness was related with decreases in the child's bullying behavior. Grade 5 bullying was also negatively associated with closeness at grade 6 , and grade 5 mother-child conflict increased the likelihood of bullying behavior at grade 6 . Therefore, bullying does not necessarily increase the conflict between parents and children, but it possibly affects the parent-child relationship through the negative effects it has on the closeness identified in the parent-child dyad. In addition, it seems that the conflict between parents and children starts to have its negative effects during early adolescence, which might be due to the transformation in the parent-child relationship during this developmental period characterized by increases in conflict and decreases in closeness $[59,60]$. Our data also support this inverse growth over time since parent-child conflict increased across time and closeness decreased across time.

There was also partial support for a transactional association between victimization and the parent-child relationship quality. Grade 3 victimization was related to increases in grade 5 closeness, suggesting that parents might respond with more closeness in reaction to the child's negative experiences associated with being a victim. Furthermore, both closeness and conflict during grade 5 seemed to influence the likelihood that a child will experience victimization at grade 6 . According to these findings, there might be a positive longitudinal transactional association between victimization and parentchild closeness, in which victimization increases closeness, although this increase in closeness might place the child at higher risk for experiencing victimization. This finding is in line with earlier claims that overinvolved or overprotective mothers, which might be indicated in the current study by higher closeness, are one factor related to victimization by peers $[13,27,28,61]$.

Additionally, school performance did not influence the transactional association between the parent-child relationship quality and bullying and victimization problems. Contrary to our predictions, instead of a transactional association between academic achievement and victimization, we identified a direct association in that school performance was related to increases in victimization. As suggested by prior research, school performance is not one of the reasons associated with bullying behavior [4,18, 41], although students who are performing well at school might be at increased risk to be targeted for victimization, as our findings and previous findings suggested [18]. We add to these findings in that school performance might not be related to victimization during middle childhood (grades 3 to 5), but it might influence victimization during the transition to adolescence.

The findings also provide evidence for a number of gender differences. In line with previous research, males scored higher on bullying than females (e.g., [3]). Moreover, mothers reported greater involvement with their daughters as compared to their sons, in accordance with work that finds adolescent females experiencing higher quality relationships with their parents than male adolescents (e.g., $[48,49]$ ). Finally, we found that girls performed better academically compared to boys, as suggested by prior research [50].

4.3. Strengths, Limitations, and Future Directions. Strengths of this investigation included a large sample of children, which enabled us to run a structural equation model and identify children at risk for pure and cooccurring bullying and victimization across time. Furthermore, the data were collected longitudinally, and we were able to test our hypotheses using a longitudinal model, thus enhancing the reliability and flexibility of our analyses [56]. However, data on conflict and closeness were based only on maternal-reports and would be further enhanced with the use of multiple informants and multiple methods, such as structured observations of children interacting with their parents [62]. Another strength of this investigation is the inclusion of both mother (closeness and conflict) and child (bullying and victimization) reports in the structural equation model, which decreased the possibility of inflated correlations due to shared method variance.

This study builds on existing relevant knowledge by examining the unique effects and contributions of bullying and victimization experiences at school on parenting characteristics over time. Future avenues of research could include mediational models between bullying and victimization experiences and parenting variables, such as the children's personality, motivation, and self perceptions. Such models would enable further understanding of the mechanisms of effects reported in the present study. In addition, because children are embedded within multiple contexts simultaneously [63-65], other social contexts, such as relationships with peers and other important adults, may impact the development of bullying and victimization.

In conclusion, the current study presents evidence for the existence of different pure and cooccurring groups of children in terms of bullying and victimization and identifies groups of children at higher risk for social (i.e., home and school) adversity. Findings suggest that both the child's academic achievement and relationship quality with his/her parents need to be taken into account for future intervention efforts to be successful. Furthermore, the present study has contributed to the literature by developing and testing a transactional model, based on longitudinal data, capable to describe the interrelation between mother-child relationship and child bullying and victimization experiences. A transactional relationship was supported between the parentchild relationship quality and bullying and victimization. The transactional findings of the current investigation support earlier claims $[14,66,67]$ that children and their mothers are intertwined in a cycle of reciprocal associations. The empirical evidence provided contributes to a better understanding of the ongoing dynamics between parents and children across development, particularly regarding bullying and victimization experiences at school. As Dodge and Pettit [68] point out, in symbiotic models of development, like the one between parent and child, influences tend to become reciprocal over time. 


\section{References}

[1] S. Headley, "Bullying and violence," Youth Studies in Australia, vol. 23, no. 2, pp. 60-69, 2004.

[2] D. Olweus, "Aggressors and their victims: bullying at school," in Disruptive Behavior in Schools, N. Frude and H. Gault, Eds., pp. 57-76, Wiley, New York, NY, USA, 1984.

[3] D. Seals and J. Young, "Bullying and victimization: prevalence and relationship to gender, grade level, ethnicity, self-esteem, and depression," Adolescence, vol. 38, no. 152, pp. 735-747, 2003.

[4] D. Olweus, Bullying at School: What We Know and What We Can Do, Blackwell, Oxford, UK, 1993.

[5] D. P. Farrington, "Understanding and preventing bullying," in Crime and Justice, M. Tonry and N. Morris, Eds., pp. 381-458, Chicago University Press, Chicago, Ill, USA, 1993.

[6] K. Rigby, New Perspective on Bullying, Jessica Kingsley, London, UK, 2002.

[7] P. Naylor, H. Cowie, and R. del Rey, "Coping strategies of secondary school children in response to being bullied," Child Psychology and Psychiatry Review, vol. 6, pp. 114-120, 2001.

[8] T. Tanaka, "The identity formation of the victim of 'Shunning"' School Psychology International, vol. 22, no. 4, pp. 463-476, 2001.

[9] R. Kaltiala-Heino, Rimpelä M, Rimpelä M, P. Rantanen, and A. Rimpelä, "Bullying at school—an indicator of adolescents at risk for mental disorders," Journal of Adolescence, vol. 23, no. 6, pp. 661-674, 2000.

[10] L. Bowers, P. K. Smith, and V. Brinney, "Cohesion and power in the families of children involved in bully/victim problems at school," Journal of Family Therapy, vol. 14, no. 4, pp. 371-387, 1992.

[11] K. A. Fanti, P. J. Frick, and S. Georgiou, "Linking callousunemotional traits to instrumental and non-instrumental forms of aggression," Journal of Psychopathology and Behavioral Assessment, vol. 31, no. 4, pp. 285-298, 2009.

[12] C. M. Kokkinos and G. Panayiotou, "Predicting bullying and victimization among early adolescents: associations with disruptive behavior disorders," Aggressive Behavior, vol. 30, no. 6, pp. 520-533, 2004.

[13] V. Stevens, I. De Bourdeaudhuij, and P. Van Oost, "Relationship of the family environment to children's involvement in bully/ victim problems at school," Journal of Youth and Adolescence, vol. 31, no. 6, pp. 419-428, 2002.

[14] A. J. Sameroff and M. J. Mackenzie, "Research strategies for capturing transactional models of development: the limits of the possible," Development and Psychopathology, vol. 15, no. 3, pp. 613-640, 2003.

[15] T. N. Beran, G. Hughes, and J. Lupart, "A model of achievement and bullying: analyses of the Canadian national longitudinal survey of children and youth data," Educational Research, vol. 50, no. 1, pp. 25-39, 2008.

[16] K. A. Berthold and J. H. Hoover, "Correlated of bullying and victimization among intermediate students in the Midwestern USA," School Psychology International, vol. 21, no. 1, pp. 65-78, 2000.

[17] G. M. Glew, M. Y. Fan, W. Katon, F. P. Rivara, and M. A. Kernic, "Bullying, psychosocial adjustment, and academic performance in elementary school," Archives of Pediatrics and Adolescent Medicine, vol. 159, no. 11, pp. 1026-1031, 2005.

[18] X. Ma, "Bullying in middle school: individual and school characteristics of victims and offenders," School Effectiveness and School Improvement, vol. 13, no. 1, pp. 63-89, 2002.
[19] S. Woods and D. Wolke, "Direct and relational bullying among primary school children and academic achievement," Journal of School Psychology, vol. 42, no. 2, pp. 135-155, 2004.

[20] D. Schwartz, "Subtypes of victims and aggressors in children's peer groups," Journal of Abnormal Child Psychology, vol. 28, no. 2, pp. 181-192, 2000.

[21] R. L. Toblin, D. Schwartz, A. H. Gorman, and T. Abou-ezzeddine, "Social-cognitive and behavioral attributes of aggressive victims of bullying," Journal of Applied Developmental Psychology, vol. 26, no. 3, pp. 329-346, 2005.

[22] A. C. Baldry and D. P. Farrington, "Bullies and delinquents: personal characteristics and parental styles," Journal of Community and Applied Social Psychology, vol. 10, no. 1, pp. 17-31, 2000.

[23] D. Schwartz, K. A. Dodge, G. S. Pettit, and J. E. Bates, "The early socialization of aggressive victims of bullying," Child Development, vol. 68, no. 4, pp. 665-675, 1997.

[24] D. L. Espelage, K. Bosworth, and T. R. Simon, "Examining the social context of bullying behaviors in early adolescence," Journal of Counseling and Development, vol. 78, no. 3, pp. 326-333, 2000.

[25] E. Flouri and A. Buchanan, "The role of mother involvement and father involvement in adolescent bullying behavior," Journal of Interpersonal Violence, vol. 18, no. 6, pp. 634-644, 2003.

[26] S. N. Georgiou, "Bullying and victimization at school: the role of mothers," British Journal of Educational Psychology, vol. 78, no. 1, pp. 109-125, 2008.

[27] S. N. Georgiou, "Parental style and child bullying and victimization experiences at school," Social Psychology of Education, vol. 11, no. 3, pp. 213-227, 2008.

[28] D. Olweus, "Familial and temperamental determinants of aggressive behavior in adolescent boys: a causal analysis," Developmental Psychology, vol. 16, no. 6, pp. 644-660, 1980.

[29] K. A. Fanti, C. C. Henrich, K. A. Brookmeyer, and G. P. Kuperminc, "Toward a transactional model of parent-adolescent relationship quality and adolescent psychological adjustment," Journal of Early Adolescence, vol. 28, no. 2, pp. 252-276, 2008.

[30] C. M. Kokkinos and G. Panayiotou, "Parental discipline practices and locus of control: relationship to bullying and victimization experiences of elementary school students," Social Psychology of Education, vol. 10, no. 3, pp. 281-301, 2007.

[31] E. Reitz, M. Deković, and A. M. Meijer, "Relations between parenting and externalizing and internalizing problem behaviour in early adolescence: child behaviour as moderator and predictor," Journal of Adolescence, vol. 29, no. 3, pp. 419-436, 2006.

[32] L. V. Scaramella, R. D. Conger, R. Spoth, and R. L. Simons, "Evaluation of a social contextual model of delinquency: a crossstudy replication," Child Development, vol. 73, no. 1, pp. 175-195, 2002.

[33] K. M. Beaver and J. P. Wright, "A child effects explanation for the association between family risk and involvement in an antisocial lifestyle," Journal of Adolescent Research, vol. 22, no. 6, pp. 640-664, 2007.

[34] K. L. Buist, M. Dekovíc, W. Meeus, and M. A. G. van Aken, "The reciprocal relationship between early adolescent attachment and internalizing and externalizing problem behaviour," Journal of Adolescence, vol. 27, no. 3, pp. 251-266, 2004.

[35] S. A. Burt, M. McGue, R. F. Krueger, and W. G. Iacono, "How are parent-child conflict and childhood externalizing symptoms related over time? Results from a genetically informative crosslagged study," Development and Psychopathology, vol. 17, no. 1, pp. 145-165, 2005. 
[36] D. Huh, J. Tristan, E. Wade, and E. Stice, "Does problem behavior elicit poor parenting? A prospective study of adolescent girls," Journal of Adolescent Research, vol. 21, no. 2, pp. 185-204, 2006.

[37] S. J. Jang and C. A. Smith, "A test of reciprocal causal relationships among parental supervision, affective ties, and delinquency," Journal of Research in Crime and Delinquency, vol. 34, no. 3, pp. 307-336, 1997.

[38] R. D. Laird, G. S. Pettit, J. E. Bates, and K. A. Dodge, "Parents' monitoring-relevant knowledge and adolescents' delinquent behavior: evidence of correlated developmental changes and reciprocal influences," Child Development, vol. 74, no. 3, pp. 752768, 2003.

[39] S. Vuchinich, L. Bank, and G. R. Patterson, "Parenting, peers, and the stability of antisocial behavior in preadolescent boys," Developmental Psychology, vol. 28, no. 3, pp. 510-521, 1992.

[40] G. R. Patterson, Coercive Family Process: A Social Learning Approach, Castalia, Eugene, Ore, USA, 1982.

[41] K. Rigby and P. T. Slee, "Bullying among Australian school children: reported behavior and attitudes toward victims," The Journal of Social Psychology, vol. 131, no. 5, pp. 615-627, 1991.

[42] S. Sharp, "How much does bullying hurt?" Educational Child Psychology, vol. 12, pp. 81-88, 1995.

[43] P. T. Slee, "Situational and interpersonal correlates of anxiety associated with peer victimisation," Child Psychiatry and Human Development, vol. 25, no. 2, pp. 97-107, 1994.

[44] D. R. Offord, M. H. Boyle, and Y. A. Racine, "The epidemiology of antisocial behavior in childhood and adolescence," in The Development and Treatment of Childhood Aggression, J. Pepler and K. H. Rubin, Eds., pp. 31-54, Erlbaum, Hillsdale, NJ, USA, 1991.

[45] E. A. Youngstrom, R. L. Findling, and J. R. Calabrese, "Who are the comorbid adolescents? Agreement between psychiatric diagnosis, youth, parent, and teacher report," Journal of Abnormal Child Psychology, vol. 31, no. 3, pp. 231-245, 2003.

[46] D. Schwartz, L. J. Proctor, and D. H. Chicn, "The aggressive victim of bullying: emotional and behavioral dysregulation as a pathway to victimization by peers," in Peer Harassment in School the Plight of the Vulnerable and Victimized, J. Juvonen and S. Graham, Eds., pp. 147-174, The Guilford Press, London, UK, 2001.

[47] M. E. Solberg, D. Olweus, and I. M. Endresen, "Bullies and victims at school: are they the same pupils?" British Journal of Educational Psychology, vol. 77, no. 2, pp. 441-464, 2007.

[48] I. Hay and A. F. Ashman, "The development of adolescents' emotional stability and general self-concept: the interplay of parents, peers, and gender," International Journal of Disability, Development and Education, vol. 50, no. 1, pp. 77-91, 2003.

[49] D. A. Kenny, Interpersonal Perception: A Social Relations Analysis, Guilford, New York, NY, USA, 1994.

[50] H. W. Marsh and A. S. Yeung, "Longitudinal structural equation models of academic self-concept and achievement: gender differences in the development of math and English constructs," American Educational Research Journal, vol. 35, no. 4, pp. 705738, 1998.

[51] B. J. Kochenderfer and G. W. Ladd, "Victimized children's responses to peers' aggression: behaviors associated with reduced versus continued victimization," Development and Psychopathology, vol. 9, no. 1, pp. 59-73, 1997.

[52] G. W. Ladd, B. J. Kochenderfer, and C. C. Coleman, "Friendship quality as a predictor of young children's early school adjustment," Child Development, vol. 67, no. 3, pp. 1103-1118, 1996.
[53] K. M. Pierce, J. V. Hamm, and D. L. Vandell, "Experiences in after-school programs and children's adjustment in first-grade classrooms," Child Development, vol. 70, no. 3, pp. 756-767, 1999.

[54] R. Pianta, Student-Teacher Relationship Scale, University of Virginia, Charlottesville, Va, USA, 1992.

[55] L. K. Muthén and B. Muthén, Mplus User's Guide, Muthén \& Muthén, Los Angeles, Calif, USA, 2007.

[56] J. D. Singer and J. B. Willett, Applied Longitudinal Data Analysis: Modeling Change and Event Occurrence, Oxford University Press, Oxford, NY, USA, 2003.

[57] L. T. Hu and P. M. Bentler, "Fit Indices in covariance structure modeling: sensitivity to underparameterized model misspecification," Psychological Methods, vol. 3, no. 4, pp. 424-453, 1998.

[58] R. B. Kline, Principles and Practice of Structural Equation Modeling, The Guilford Press, New York, NY, USA, 1998.

[59] W. A. Collins and B. Laursen, "Parent-adolescent relationships and influences," in Handbook of Adolescent Psychology, R. M. Lerner and L. Steinberg, Eds., pp. 331-361, Wiley, New York, NY, USA, 2nd edition, 2004.

[60] R. L. Paikoff and J. Brooks-Gunn, "Do parent-child relationships change during puberty?” Psychological Bulletin, vol. 110, no. 1, pp. 47-66, 1991.

[61] S. Perren and R. Hornung, "Bullying and delinquency in adolescence: victims' and perpetrators' family and peer relations," Swiss Journal of Psychology, vol. 64, no. 1, pp. 51-64, 2005.

[62] J. P. Allen, K. B. McElhaney, G. P. Kuperminc, and K. M. Jodl, "Stability and change in attachment security across adolescence," Child Development, vol. 75, no. 6, pp. 1792-1805, 2004.

[63] U. Bronfenbrenner, "Interacting systems in human development. Research paradigms: present and future," in Persons in Context: Developmental Processes, N. Bolger, A. Caspi, G. Downey, and M. Moorehouse, Eds., pp. 25-49, Cambridge University Press, New York, NY, USA, 1988.

[64] D. Cicchetti and M. Lynch, "Toward an ecological/transactional model of community violence and child maltreatment: consequences for children's development," Psychiatry, vol. 56, no. 1, pp. 96-118, 1993.

[65] C. C. Henrich, K. A. Brookmeyer, L. A. Shrier, and G. Shahar, "Supportive relationships and sexual risk behavior in adolescence: an ecological-transactional approach," Journal of Pediatric Psychology, vol. 31, no. 3, pp. 286-297, 2006.

[66] S. Lollis and L. Kuczynski, "Beyond one hand clapping: seeing bidirectionality in parent-child relations," Journal of Social and Personal Relationships, vol. 14, no. 4, pp. 441-461, 1997.

[67] A. J. Sameroff, "Transactional models in early social relations," Human Development, vol. 18, pp. 65-79, 1975.

[68] K. A. Dodge and G. S. Pettit, "A biopsychosocial model of the development of chronic conduct problems in adolescence," Developmental Psychology, vol. 39, no. 2, pp. 349-371, 2003. 

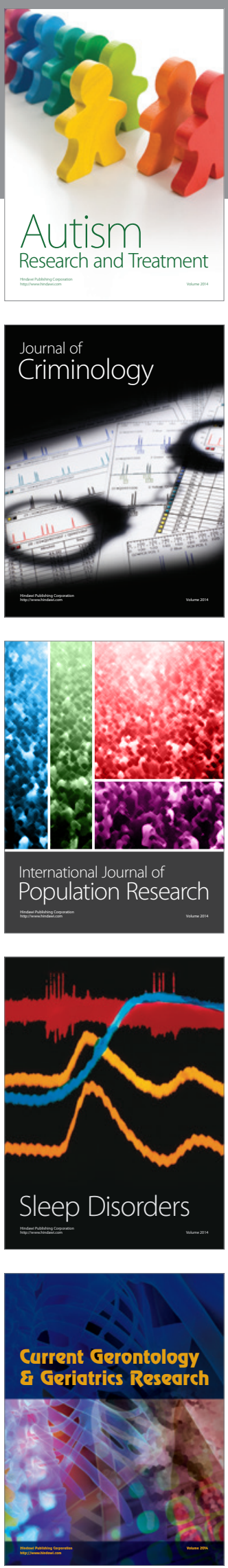
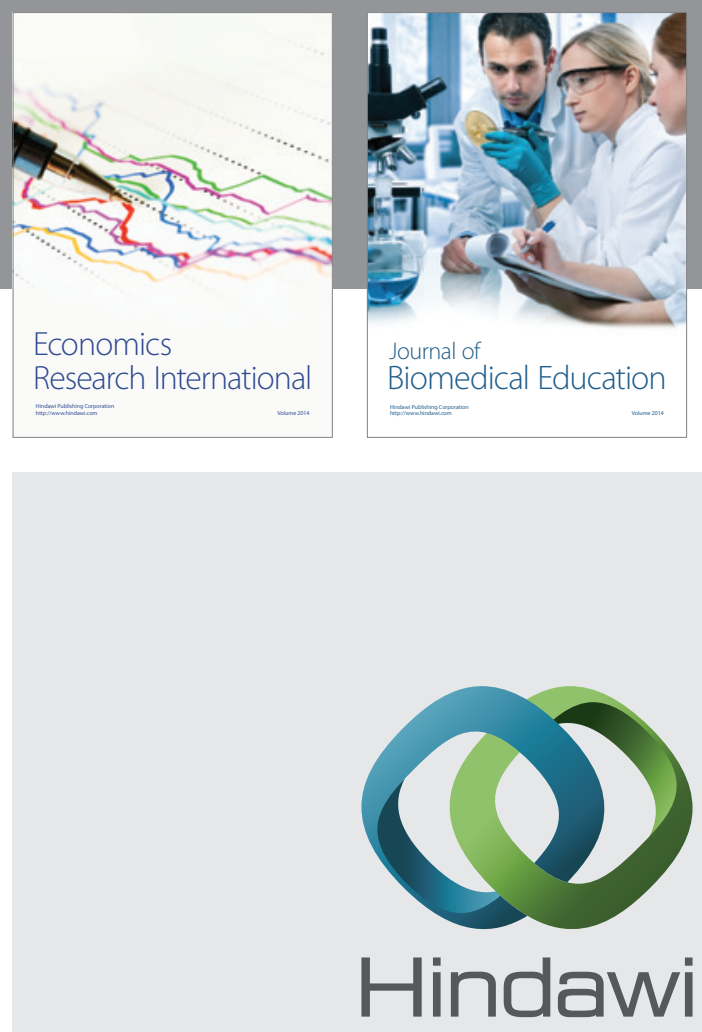

Submit your manuscripts at

http://www.hindawi.com
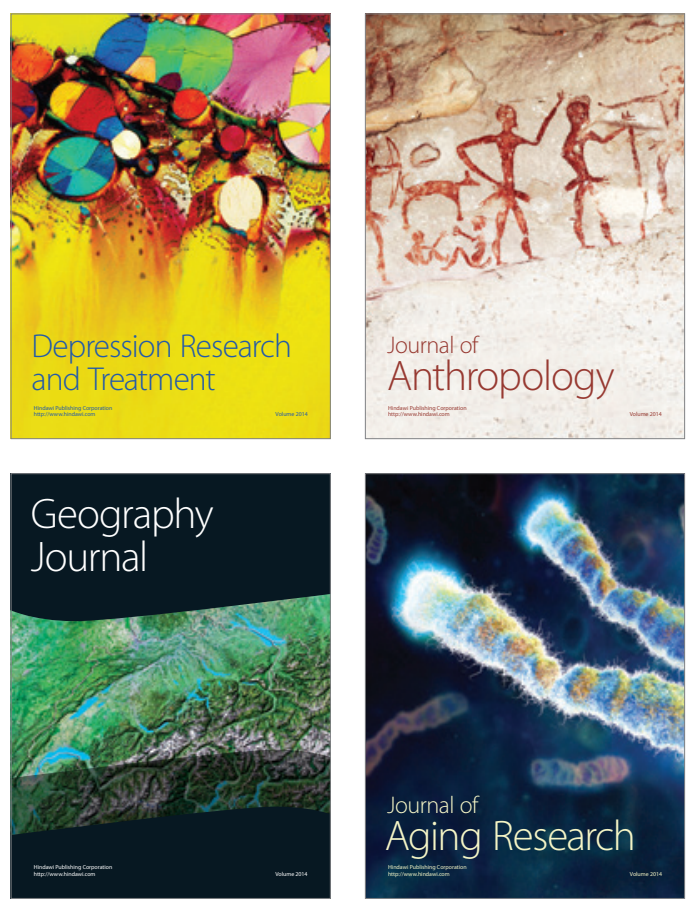
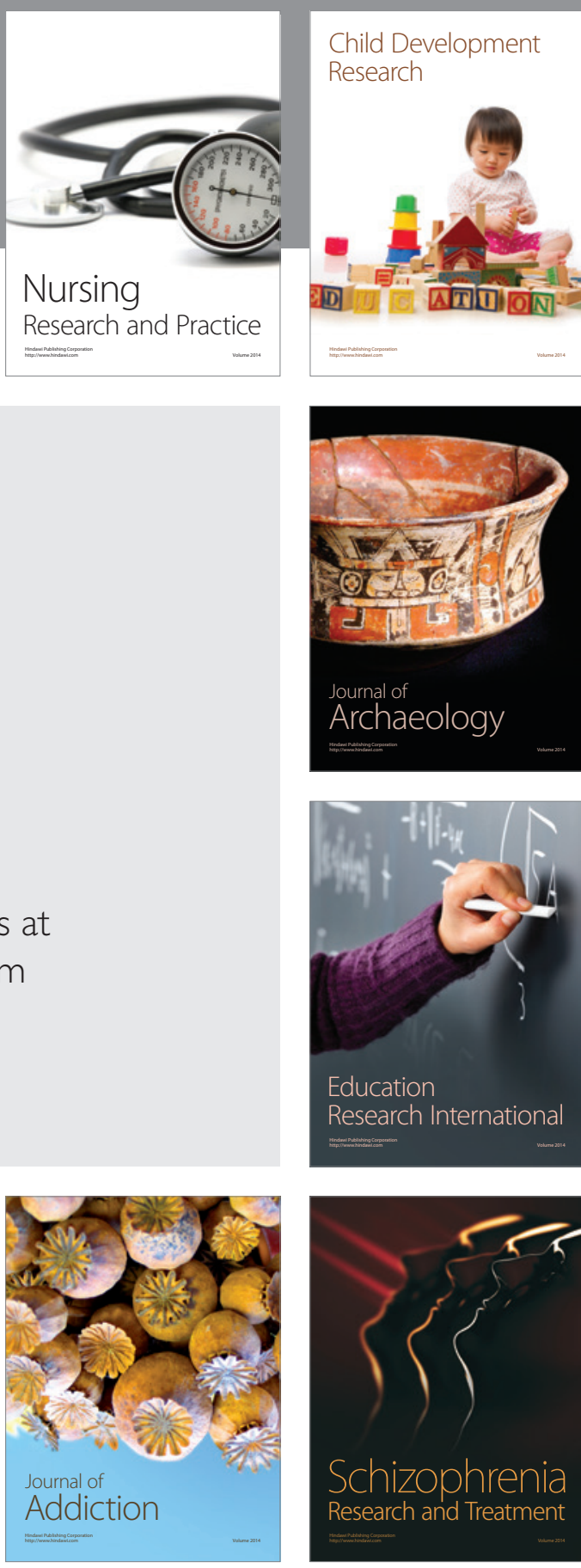

(D)
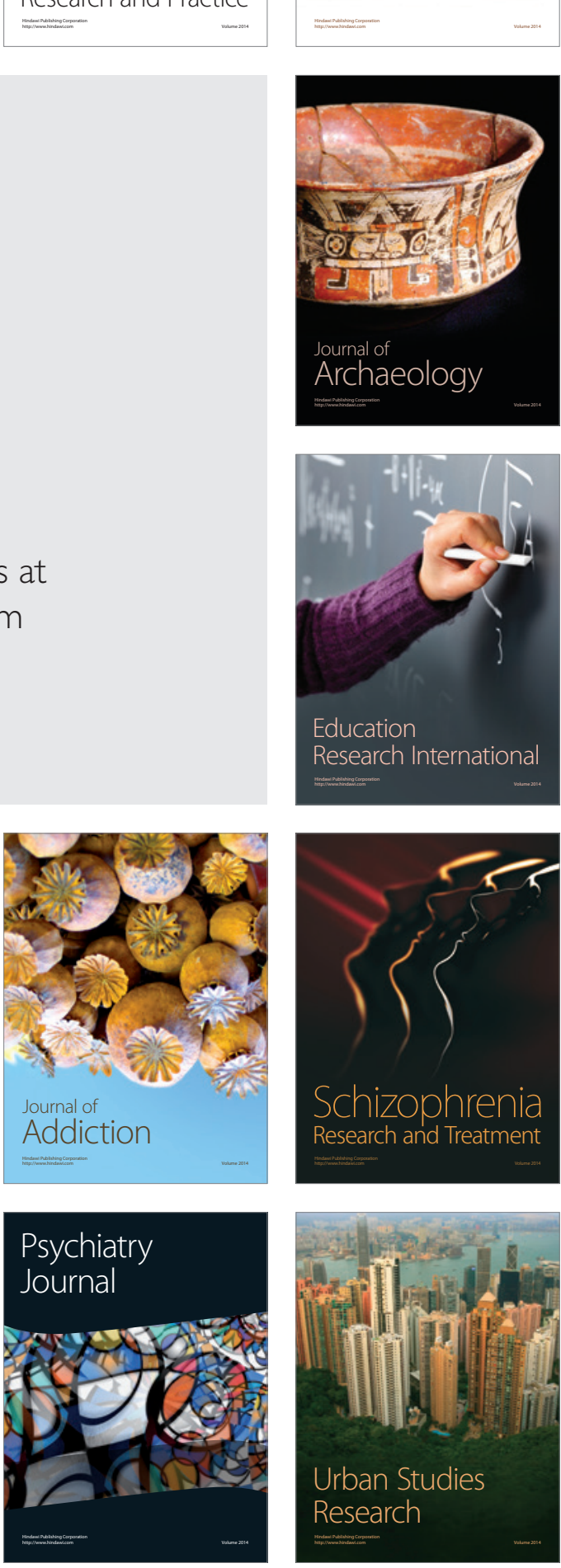